\title{
Physiotherapeutic acute low back pain interventions in the private health sector of the Cape Metropole, South Africa.
}

ABSTRACT: Objective: To rigorously evaluate the outcomes of physiotherapeutic interventions in patients with acute low back pain (LBP) within a clinical context.

Methods: A multi-centre prospective case-series study design was used. Eight private physiotherapy practices within the Cape Metropole, Cape Town, South Africa, each screened and recruited 12 eligible patients with acute LBP. Main outcome measures included pain and functional status.

Data analysis: Demographic information, as well as pain and disability scores were descriptively analyzed using means, standard deviations and confidence intervals. The percentage change in pain was determined by the formula (100*painvisit2-painvisit1/painvisit1) and the significance level was set at $p=0.05$. Forward stepwise logistic regression was conducted to determine predictors of good pain and disability outcomes.

Results: 48 subjects with acute LBP participated in this study (24 male and 24 female; mean age was 41.65 (SD 13.34). All scores except pain scores in the previous week, significantly improved $(P<0.05)$. For disability, the difference between all visits bar the 10th visit was significant. No significant predictors for pain and disability for the final pain and disability score were found (crude odds calculations).

Conclusion: The study illustrates that physiotherapy management interventions based on the interpretation of individual physiotherapists in a real-life scenario, yield positive outcomes with respect to momentary pain and disability scores. With over 27 different combinations of treatment modalities used across the participating practices, conclusions as to the most effective physiotherapy treatment regimens for acute episodes of non-specific LBP in private practice cannot be made.

\section{KEY WORDS: PHYSIOTHERAPY, ACUTE LOW BACK PAIN, PAIN AND DISABILITY.}

\section{Introduction}

Low back pain (LBP) is arguably the most common condition treated by private practice physiotherapists working in developed countries (Ferguson et al 2008). Despite the alarmingly high prevalence of LBP in Africa and the fact that the prevalence compares to developed countries; none of the published African studies included LBP patients treated in private practice (Louw et al 2007a). The lack of information about

\section{Correspondence to:}

Prof QA Louw

Faculty of Health Sciences,

Stellenbosch University,

P O Box 19063,

Tygerberg, 75

South Africa,

E-mail: qalouw@sun.ac.za this population should be of serious concern to the physiotherapy professional organizations negotiating with medical aid schemes for physiotherapy LBP modality tariffs in developing countries. Basic information about the burden of LBP among patients presenting with the condition such as patterns of improvement and short- and longterm outcomes of treatment can be useful to both the professional organization as well as medical aid schemes. The information can be used to plot the trends of LBP patients over time, provide directions about the educational needs of physiotherapists treating LBP patients and identify benchmarks to assess the effectiveness of interventions. Therefore, research into LBP patients in the private sector in developing countries is justified.

Currently more than 600 trials into the effectiveness of physiotherapeutic interventions for LBP have been conducted (Koes and van Tulder 2006). However, evidence emanating from clinical trials in this population is often disappointing as it does not provide clear direction about the effectiveness of specific interventions since the evidence is often equivocal (Louw et al 2007b). The interventions applied in clinical trials are also often questionable, as it does not include the usual package of physiotherapy in terms of the combination of treatment modalities and treatment duration. Physiotherapists also claim that clinical reasoning applied in real-life clinical practice is lacking in clinical trials as the type of intervention is predetermined. A further concern for physiotherapists in South Africa is that none of the trials have been conducted in South Africa and therefore the findings of the published studies may not be relevant to the South African 
population. Therefore, pragmatic methods to assist local physiotherapists in making decisions about LBP management should be explored.

Clinical evidence for interventions is hampered by poor recording and lack of outcome measurement. This paper reports on the effectiveness of LBP interventions based on clinical reasoning skills and real-life physiotherapy treatment programs applied by physiotherapists in private practice. The overall aim of this study was to rigorously evaluate the outcomes of acute LBP patients who receive physiotherapy in a real-life clinical context. The specific primary study objectives were: 1) to screen the primary confounding factors for LBP (psychosocial factors, history of LBP and personal demographics) at the commencement of treatment and 2) to assess the outcomes (pain and disability) at every physiotherapy visit until completion of treatment. Secondary objectives of the study included to evaluate and describe the various treatment regimens used by private physiotherapists in the Cape Metropole, South Africa, to treat acute LBP.

\section{Methodology}

Ethical approval was obtained from the Health Research Ethics Committee at the Stellenbosch University prior to the commencement of this study. The study was conducted at private physiotherapy practices situated in the Cape Metropole area, Cape Town (South Africa), who were registered on a LBP network. A multi-centre prospective case-series was conducted over a period of 3 months, between April and June 2009.

Currently, there are approximately 28 private physiotherapy practices from Cape Town registered on a LBP network of private practice physiotherapists who attended an updated course about LBP physiotherapy management and evidence-based physiotherapy for LBP in 2007. A computer-generated random numbers table was used to randomly select eight physiotherapy practices from the Cape Town LBP network list. The randomly-selected physiotherapy practices were contacted between October and December 2008, and invited to act as research assistants in this study.

\section{Subjects}

Patients were eligible for recruitment if they were aged 18 - 65 years old, and attended the participating physiotherapy clinics with a clinical presentation that fulfilled the criteria for idiopathic acute LBP. Idiopathic acute LBP is defined for this project as 'an acute presentation of a never-previously experienced problem (acute), or an exacerbation of an existing condition (sub-acute)'. Duration of pain should have been less than three months, with a period of pain-free function of at least three months prior to the index LBP episode. Individuals were excluded if they met any criteria for 'Red Flags' (Micturation difficulty, incontinence, saddle paraesthesia/anaesthesia, widespread or progressive weakness in legs), had chronic LBP (LBP for longer than 3 months), or LBP associated with pregnancy. These conditions involved other patho-biological and patho-behavioural agents that possibly required different management strategies.

\section{Study procedures}

\section{Consent and initial data collection}

The eight randomly-selected physiotherapy practices were contacted telephonically or invited via email to participate in this study. On agreeing to participate in the study, the physiotherapists working in the practices were required to read and sign an informed consent form. The participating physiotherapists' responsibilities during the study included: acting as research assistants, recruiting 12 acute LBP patients who met the inclusion criteria of the study, obtaining patients' written consent, and overseeing patient treatment and outcomes. The physiotherapists were also expected to collect the demographic details (using a specifically designed demographic form) and outcome measures for eligible patients, using standard written forms/measures. Demographic details included home address, telephone numbers, age, gender, occupation, working status (including absence from work for LBP), previous episodes of LBP (including previous and usual methods of management), and psychosocial factors "yellow flag screening" (New Zealand guidelines 2004). A package containing the demo- graphic forms, pre-treatment information, ongoing assessment forms, as well as outcome measurement tools for a total of 12 patients were given to each participating physiotherapy practice prior to commencement of data collection. The ongoing assessment form included the following sections: 1) number / type of PT treatments in index episode of care; 2) medication use and type; 3) type and frequency of other treatment sought; and 4) days lost from work/usual activity.

\section{Outcome measures}

All physiotherapists registered on the 2007 LBP network received training on how to administer the outcome measures during the LBP courses. The outcome measures were administered pre-treatment and at each treatment session for a maximum of 10 visits or until discharge, whichever came first. The outcome measures chosen for this study are reported as sensitive, valid and reliable for patients with idiopathic acute LBP (Australian acute musculoskeletal pain guidelines group 2004) and are the following:

1) Pain intensity and frequency (Visual Analogue Scales)

2) Functional status (Roland- Morris Disability Scale)

Each physiotherapist and patient was identified by a number allocated to them. This information was blinded to the researcher responsible for data analysis, but not from the project officer. At the end of the data collection period, the data were collected from each participating physiotherapy practice by the project officer.

\section{Physiotherapy treatments}

Treatment for LBP was determined by each physiotherapist using a clinical reasoning process based on individual patient assessment and requirements. Thus, each treatment protocol varied per patient across participating practices. The type of each treatment modality was recorded at each visit up until the patient was discharged from treatment, the tenth visit or if the patient discontinued treatment. If subjects were referred for further investigation or treatments, this information was recorded. 


\section{Data Analysis}

Demographic information as well as pain and disability scores were descriptively analysed using means (M), standard deviations (SD) and 95\% confidence intervals $(95 \% \mathrm{CI})$. The percentage change in pain was determined by the formula (100* painvisit2-painvisit1/ painvisit1) and the significance level was set at $p=0.05$. Forward stepwise logistic regression was conducted to determine predictors of good pain and disability outcomes.

\section{Results}

Participant description and initial pain and disability scores

A total of 50 subjects with LBP were recruited by the eight physiotherapy practices over the stipulated data collection period. Two subjects were not included in the analysis as insufficient information was recorded. Table 1 illustrates the demographic information for 48 of the 50 eligible subjects, as well as the initial pain and disability scores. The initial pain and disability scores for male and female subjects were not significantly different $(\mathrm{p}>0.05)$.

Initial and final mean pain and disability scores

Table 2 provides a summary of the mean pain and disability scores at each visit and the $95 \%$ CIs to provide a population estimate.

Mean percentage change in pain between the first and last visit

Table 3 illustrates the percentage (\%) change in pain between the first and the last treatment sessions. All scores, bar the pain score in the past week, significantly improved $(\mathrm{P}<0.05)$.

Mean percentage change in pain and disability scores

Figure 1 illustrates the mean change in pain scores (for pain today) for each visit (second to the tenth visit compared to the first visit). The difference between all visits except the 10th visit was significant.

Figure 2 illustrates the mean change in pain scores (for pain the day before) for each visit (second to the tenth visit compared to the first visit). The findings
Table 1: Demographic summary and description of initial pain and disability scores

\begin{tabular}{|l|l|l|l|}
\cline { 2 - 4 } \multicolumn{1}{l|}{} & All & Male & Female \\
\hline Age $(\mathrm{n}=46)$ & $41.65 \pm 13.34$ & $\begin{array}{l}37.41 \pm 12.13 \\
\mathrm{n}=22\end{array}$ & $\begin{array}{l}45.54 \pm 13.44 \\
\mathrm{n}=24\end{array}$ \\
\hline Nr of visits $(\mathrm{n}=49)$ & $4.61 \pm 2.68$ & $\begin{array}{l}5.3 \pm 2.58 \\
\mathrm{n}=23\end{array}$ & $\begin{array}{l}4.20(2.66) \\
\mathrm{n}=24\end{array}$ \\
\hline $\begin{array}{l}\text { Yellow flag score } \\
\text { (n=35) }\end{array}$ & $89.23 \pm 17.91$ & $\begin{array}{l}89.52 \pm 18.57 \\
\mathrm{n}=21\end{array}$ & $\begin{array}{l}88.78(17.54) \\
\mathrm{n}=14\end{array}$ \\
\hline $\begin{array}{l}\text { Initial pain score for } \\
\text { today ( } \mathrm{n}=48)\end{array}$ & $6.27 \pm 2.38$ & $\begin{array}{l}6.48 \pm 2.21 \\
\mathrm{n}=23\end{array}$ & $\begin{array}{l}6.25(2.45) \\
\mathrm{n}=24\end{array}$ \\
\hline $\begin{array}{l}\text { Initial pain score for } \\
\text { previous day ( } \mathrm{n}=48)\end{array}$ & $7.06 \pm 2.15$ & $\begin{array}{l}7.47 \pm 1.80 \\
\mathrm{n}=23\end{array}$ & $\begin{array}{l}6.83(2.33) \\
\mathrm{n}=24\end{array}$ \\
\hline $\begin{array}{l}\text { Initial pain score for } \\
\text { previous week ( } \mathrm{n} 48)\end{array}$ & $6.43 \pm 3.32$ & $\begin{array}{l}6.51 \pm 3.61 \\
\mathrm{n}=23\end{array}$ & $\begin{array}{l}6.41(3.16) \\
\mathrm{n}=24\end{array}$ \\
\hline $\begin{array}{l}\text { Initial Roland Morris } \\
\text { score ( } \mathrm{n}=47)\end{array}$ & $10.35 \pm 4.75$ & $\begin{array}{l}11.91 \pm 3.88 \\
\mathrm{n}=23\end{array}$ & $\begin{array}{l}9.08(5.13) \\
\mathrm{n}=24\end{array}$ \\
\hline
\end{tabular}

Table 2: Description of mean pain and disability $(n=48)$

\begin{tabular}{|l|l|}
\cline { 2 - 2 } \multicolumn{1}{l|}{} & Mean $(95 \% \mathrm{CI})$ \\
\hline Initial pain for today & $1.27(5.58-6.96)$ \\
\hline Final pain for today & $1.75(2.14-3.36)$ \\
\hline Initial pain for previous day & $1.6 \quad(6.44-7.89)$ \\
\hline Final pain for previous day & $1.36(2.84-3.88)$ \\
\hline Final pain for previous week & $1.43(5.47-7.40)$ \\
\hline Initial Roland Morris Score & $10.35(8.97-11.73)$ \\
\hline Final Roland Morris Score & $1.52(3.48-5.55)$ \\
\hline
\end{tabular}

Table 3: Percentage change in pain and disability scores between the first and last session $(\mathrm{N}=48)$

\begin{tabular}{|l|l|l|l|}
\cline { 2 - 4 } \multicolumn{1}{c|}{} & Mean & Median & $\mathbf{9 5 \%}$ Cl for mean \\
\hline $\begin{array}{l}\text { Change in pain score } \\
\text { (first day of treatment - day 1) }\end{array}$ & $-53.63 \%$ & -57.14 & -62.15 to -45.10 \\
\hline $\begin{array}{l}\text { Change in pain score } \\
\text { (previous day) }\end{array}$ & $-39.10 \%$ & -58.57 & -67.36 to -10.84 \\
\hline $\begin{array}{l}\text { Change in pain score } \\
\text { (previous week) }\end{array}$ & $48.65 \%$ & -19.44 & -14.31 to 111.62 \\
\hline $\begin{array}{l}\text { Change in Roland- } \\
\text { Morris score }\end{array}$ & $-52.36 \%$ & -60.77 & -62.17 to -42.53 \\
\hline
\end{tabular}


Figure 1: Mean pain change ( $\%$ change) for momentary pain

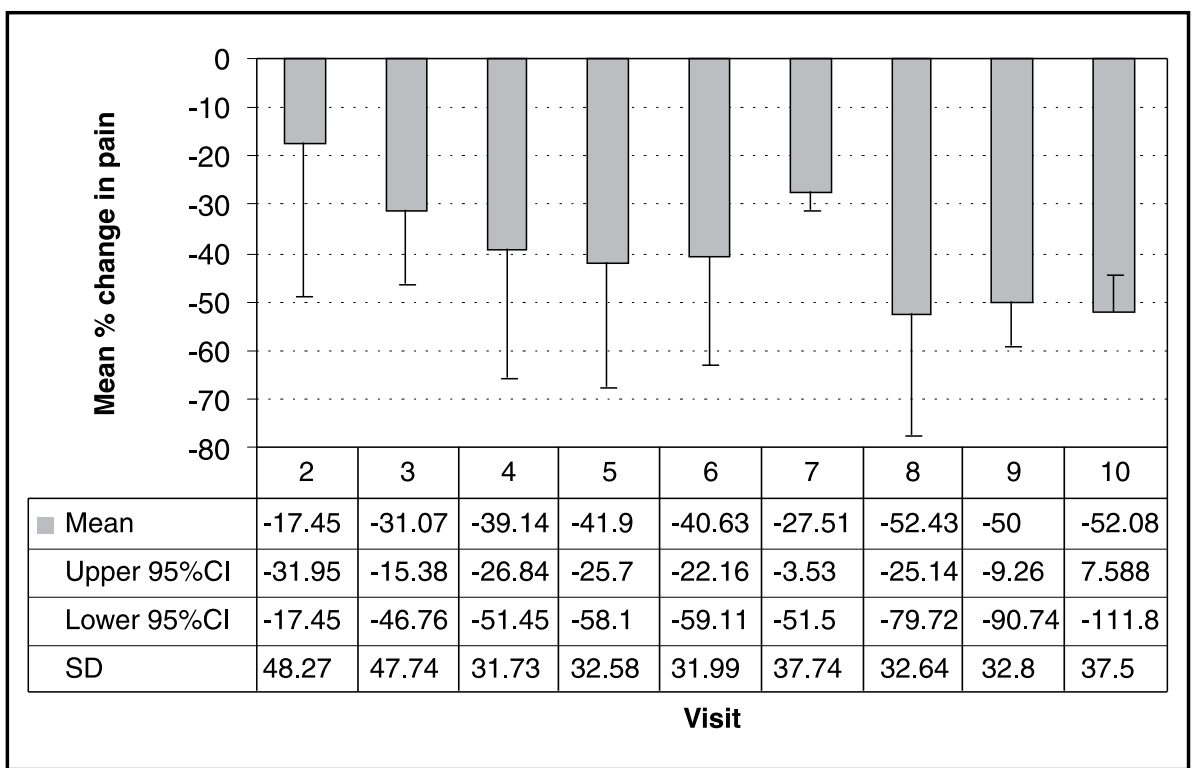

Figure 2: Mean pain change ( $\%$ change) between day of treatment and previous day

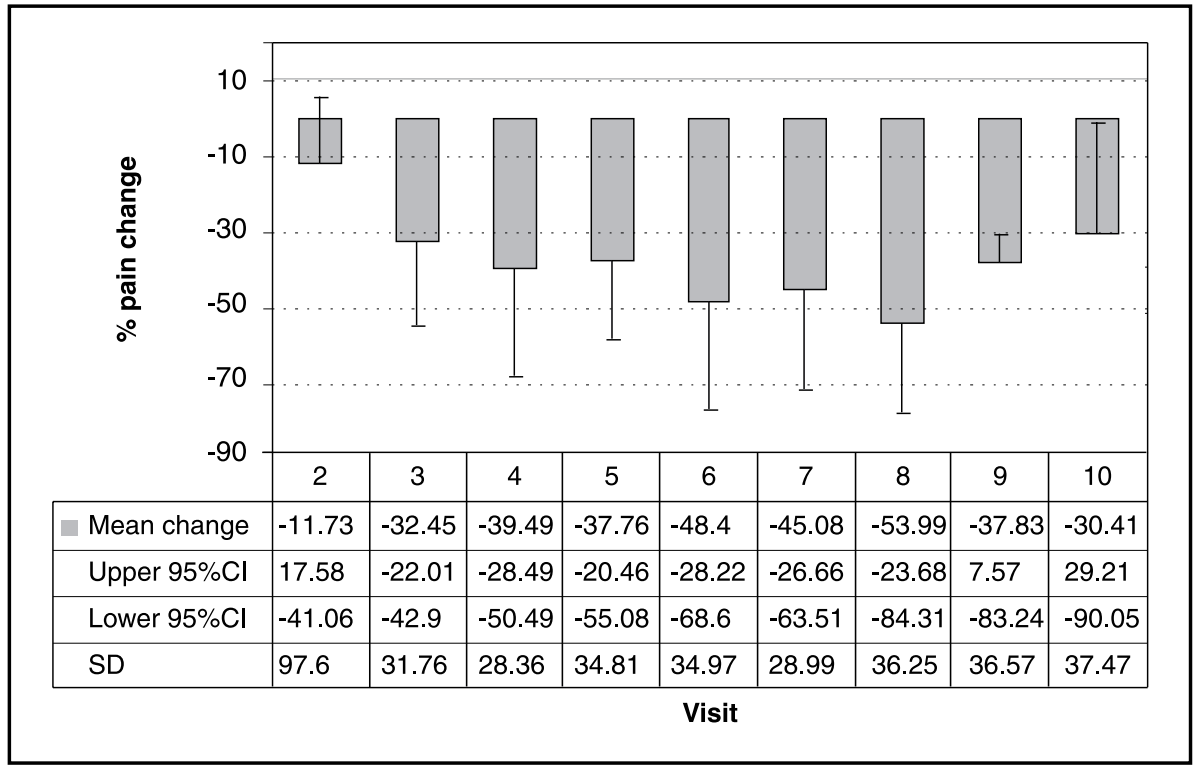

Figure 3: Mean pain change ( $\%$ change) for pain previous week

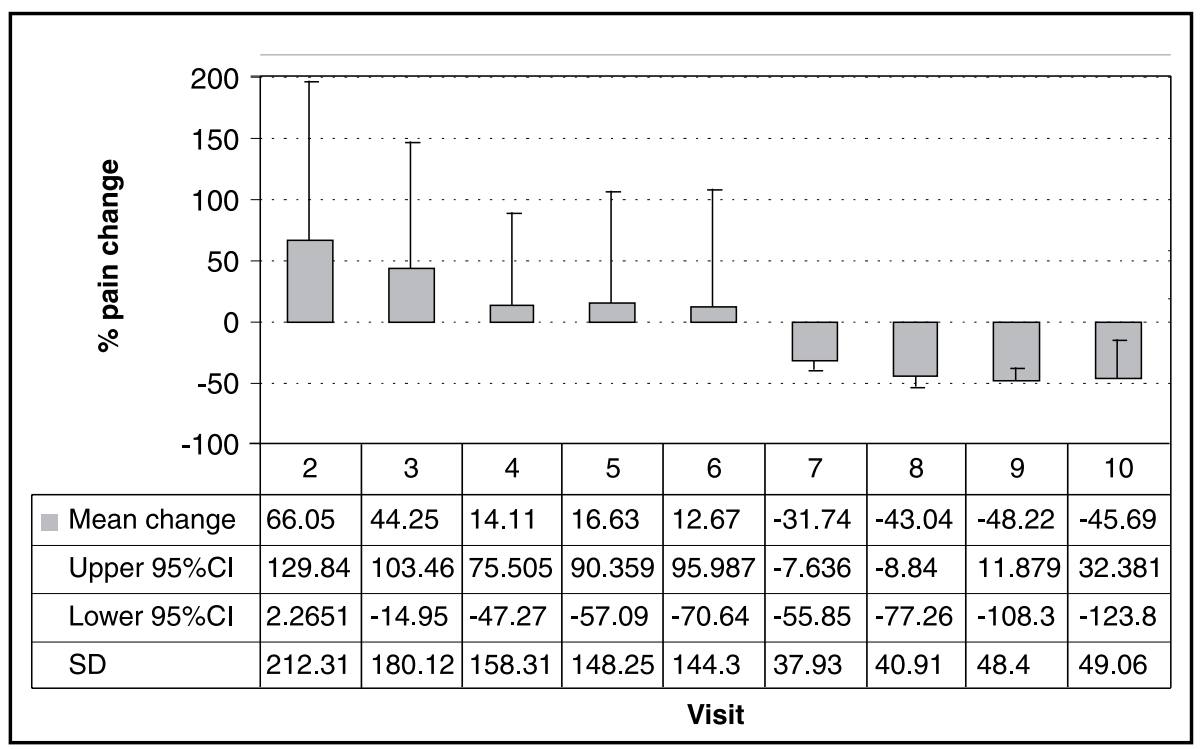

illustrate that most of the pain scores significantly reduced, except for visit 2 , 9 and 10.

Figure 3 illustrates the mean change in pain scores (for pain in the previous week) for each visit (second to the tenth visit compared to the first visit). There was only a significant reduction in pain scores for the 7 th and 8 th visit.

\section{Predictors of good pain outcome}

A percentage decrease in initial pain of $57 \%$ (group was split at the median) was regarded as a good outcome in pain. No significant predictors for pain following the final treatment (crude odds calculations) were found (see table 4). When adjusted for confounders, no significant predictors for pain were found (see table 5).

Predictors of good disability outcome A percentage change in disability of less than $60 \%$ of the initial RolandMorris score was regarded as a good disability outcome. No significant predictors for disability could be found (although there was a tendency for a better outcome if the yellow flag score was low) (see table 6).

\section{Physiotherapy treatment modalities}

At each of the participating physiotherapy practices, the treating physiotherapist used a variety of physiotherapy treatment modalities to treat the LBP patients. Table 7 illustrates the proportion of physiotherapy treatment modalities used at each visit. Spinal mobilization was the most common treatment modality used and was used in different combinations of treatments during the first treatment session. Spinal mobilization consisted of the following: Maitland's mobilizations of the spine, McKenzie's extension spinal mobilization, and Mulligan's mobilization of the spine and lumbar rotations. Specific grades of the spinal mobilizations were not provided. Spinal mobilizations constituted between 13 and $31 \%$ of the treatment regimen across the ten treatment sessions. Electrotherapy modalities (which were namely heat, ultrasound, and interferential therapy) constituted 3 to $27 \%$ of treatment sessions. Exercises 
Table 4: Crude odds for predicting good pain outcome

\begin{tabular}{|l|l|l|l|}
\hline Variable & $\begin{array}{l}\text { Crude } \\
\text { OR }\end{array}$ & $95 \%$ Cl & p-value \\
\hline $\begin{array}{l}\text { Number of visits } \\
\text { (less than 4 visits) }\end{array}$ & 0.6 & $0.14-2.58$ & 0.49 \\
\hline $\begin{array}{l}\text { Age } \\
\text { (older than 38 years) }\end{array}$ & 0.28 & $0.06-1.27$ & 0.10 \\
\hline $\begin{array}{l}\text { Severity } \\
\text { (more than 5) }\end{array}$ & 2.5 & $0.55-11.25$ & 0.23 \\
\hline Yellow flag score $>90$ & 1.01 & $0.96-1.05$ & 0.62 \\
\hline
\end{tabular}

Table 5: Adjusted odds for predicting good pain outcome

\begin{tabular}{|l|l|l|l|}
\hline Variable & $\begin{array}{l}\text { Adjusted } \\
\text { OR }\end{array}$ & $\begin{array}{l}\text { Adjusted } \\
\mathbf{9 5 \% ~ C l}\end{array}$ & p-value \\
\hline $\begin{array}{l}\text { Number of visits } \\
\text { (less than 4 visits) }\end{array}$ & 1.15 & $0.23-5.61$ & 0.86 \\
\hline $\begin{array}{l}\text { Age } \\
\text { (older than 38 years) }\end{array}$ & 0.23 & $0.04-1.19$ & 0.08 \\
\hline $\begin{array}{l}\text { Severity } \\
\text { (more than 5) }\end{array}$ & 3.27 & $0.63-17.08$ & 0.16 \\
\hline Yellow flag score >90 & 1.0 & $0.96-1.05$ & 0.99 \\
\hline
\end{tabular}

Table 6: Crude odds for predicting good disability outcome

\begin{tabular}{|l|l|l|l|}
\hline Variable & $\begin{array}{l}\text { Crude } \\
\text { OR }\end{array}$ & $95 \% \mathbf{C l}$ & p-value \\
\hline $\begin{array}{l}\text { Number of visits } \\
\text { (less than 4 visits) }\end{array}$ & 0.49 & $0.12-1.97$ & 0.31 \\
\hline $\begin{array}{l}\text { Age } \\
\text { (older than 38 years) }\end{array}$ & 0.47 & $0.12-1.85$ & 0.28 \\
\hline $\begin{array}{l}\text { Severity } \\
\text { (more than 5) }\end{array}$ & 0.67 & $0.16-2.93$ & 0.6 \\
\hline Yellow flag score >90 & 1.0 & $0.97-1.04$ & 0.82 \\
\hline
\end{tabular}

Key: OR $=$ Odds ratios

constituted 13 to $30 \%$ of treatments and consisted of active exercises, abdominal rehabilitation, stabilization exercises, and stretches. The proportion of exercises increased as the number of treatment sessions increased and progressed. Other physiotherapy treatment modalities used were neural tissue mobilization, trigger point therapy, traction, dry needling and bed rest. Dry needling was used by one physiotherapy practice and bed rest was only advised once by one physiotherapist.

A total of 27 different combinations of treatment modalities were used across the eight physiotherapy practices in the first treatment session for acute LBP subjects. Table 8 illustrates the five most common combinations of treatment modalities used in the first treatment session. The most common combination of treatment modalities during the first treatment session was: spinal mobilizations, electrotherapy and back advice

Types of other treatment sought and medication used

$24 \%(\mathrm{n}=12)$ of the included subjects reported the use of other types of and education. therapies namely occupational therapy, corset usage and drug therapy. The drugs included: Non-steroidal anti-inflammatory drugs, Spasmend, Voltaren, Celebrex, Coxflam, Panado, Betamax, Mybulin, Pax, and Synap Forte. Specific information regarding each type of therapy such as frequency or dosage was not provided.

\section{Days lost from work}

The highest number of days missed from work by a subject was 14 days. Seven acute LBP subjects (14\%) lost between 1 and 14 days from work. The rest did not lose any days from work. Some subjects were retired; housewives or students and days lost from work therefore did not apply to them.

\section{Discussion}

This paper reports on the effect of physiotherapeutic interventions on pain and disability experienced by acute LBP patients, based on usual clinical reasoning skills and real-life physiotherapy management applied by physiotherapists in private practice within the Cape Metropole area, Cape Town (South Africa). This paper also reports on the physiotherapy treatment regimens currently utilized by private physiotherapists within the Cape Metropole to treat acute idiopathic LBP. The study illustrates that physiotherapy management interventions based on the interpretation of individual physiotherapists in a real-life scenario, yield positive outcomes with respect to momentary pain and disability scores. However, since the physiotherapy management for acute LBP varied considerably amongst the participating practices, concrete recommendations as to the most effective physiotherapy management regimens for acute LBP in private practice cannot be made.

The demographic information of this sample compares well with acute LBP subjects included in other African studies (Louw et al 2007a). However, the sample size is currently too small to ascertain if it is representative of the entire adult population with acute LBP in the Western Cape. There is currently insufficient data to ascertain the sampling error, although it appears that female subjects 
Table 7: Frequency of use of each Physiotherapy modalities per treatment and \% overall use for entire cohort (visit 1 to 10$)$

\begin{tabular}{|c|c|c|c|c|c|c|c|c|c|c|}
\hline Modality & $\begin{array}{l}R \times 1 \\
(n=49)\end{array}$ & $\begin{array}{l}R \times 2 \\
(n=47)\end{array}$ & $\begin{array}{l}R \times 3 \\
(n=37)\end{array}$ & $\begin{array}{l}R \times 4 \\
(n=27)\end{array}$ & $\begin{array}{l}R \times 5 \\
(n=18)\end{array}$ & $\begin{array}{l}R \times 6 \\
(n=14)\end{array}$ & $\begin{array}{l}R \times 7 \\
(n=13)\end{array}$ & $\begin{array}{l}R \times 8 \\
(n=7)\end{array}$ & $\begin{array}{l}R \times 9 \\
(n=5)\end{array}$ & $\begin{array}{l}R \times 10 \\
(n=4)\end{array}$ \\
\hline Spinal mobs & $\begin{array}{l}49 \\
(31 \%)\end{array}$ & $\begin{array}{l}46 \\
(29 \%)\end{array}$ & $\begin{array}{l}36 \\
(30 \%)\end{array}$ & $\begin{array}{l}26 \\
(27 \%)\end{array}$ & $\begin{array}{l}16 \\
(26 \%)\end{array}$ & $\begin{array}{l}11 \\
(29 \%)\end{array}$ & $\begin{array}{l}9 \\
(27 \%)\end{array}$ & $\begin{array}{l}5 \\
(28 \%)\end{array}$ & $\begin{array}{l}1 \\
(13 \%)\end{array}$ & $\begin{array}{l}2 \\
(25 \%)\end{array}$ \\
\hline $\begin{array}{l}\text { Soft tissue } \\
\text { mobs/massage/MFR }\end{array}$ & $\begin{array}{l}25 \\
(16 \%)\end{array}$ & $\begin{array}{l}26 \\
(16 \%)\end{array}$ & $\begin{array}{l}20 \\
(16 \%)\end{array}$ & $\begin{array}{l}10 \\
(8 \%)\end{array}$ & $\begin{array}{l}4 \\
(7 \%)\end{array}$ & $\begin{array}{l}2 \\
(5 \%)\end{array}$ & $\begin{array}{l}3 \\
(9 \%)\end{array}$ & $\begin{array}{l}1 \\
(6 \%)\end{array}$ & & \\
\hline ET (US, IF, heat) & $\begin{array}{l}31 \\
(20 \%)\end{array}$ & $\begin{array}{l}31 \\
(20 \%)\end{array}$ & $\begin{array}{l}25 \\
(20 \%)\end{array}$ & $\begin{array}{l}20 \\
(21)\end{array}$ & $\begin{array}{l}12 \\
(20 \%)\end{array}$ & $\begin{array}{l}8 \\
(21 \%)\end{array}$ & $\begin{array}{l}5 \\
(3 \%)\end{array}$ & $\begin{array}{l}5 \\
(28 \%)\end{array}$ & $\begin{array}{l}2 \\
(25 \%)\end{array}$ & $\begin{array}{l}1 \\
(13 \%)\end{array}$ \\
\hline Exercises / stretches & $\begin{array}{l}20 \\
(13 \%)\end{array}$ & $\begin{array}{l}26 \\
(16 \%)\end{array}$ & $\begin{array}{l}19 \\
(16 \%)\end{array}$ & $\begin{array}{l}20 \\
(21 \%)\end{array}$ & $\begin{array}{l}14 \\
(23 \%)\end{array}$ & $\begin{array}{l}11 \\
(29 \%)\end{array}$ & $\begin{array}{l}10 \\
(30 \%)\end{array}$ & $\begin{array}{l}5 \\
(28 \%)\end{array}$ & $\begin{array}{l}3 \\
(60 \%)\end{array}$ & $\begin{array}{l}3 \\
(75 \%)\end{array}$ \\
\hline $\begin{array}{l}\text { Back advice/ } \\
\text { education }\end{array}$ & $\begin{array}{l}14 \\
(9 \%)\end{array}$ & $\begin{array}{l}16 \\
(10 \%)\end{array}$ & $\begin{array}{l}12 \\
(10 \%)\end{array}$ & $\begin{array}{l}11 \\
(12 \%)\end{array}$ & $\begin{array}{l}9 \\
(50 \%)\end{array}$ & $\begin{array}{l}2 \\
(5 \%)\end{array}$ & $\begin{array}{l}3 \\
(9 \%)\end{array}$ & & & \\
\hline Neural tissue mobs & $\begin{array}{l}8 \\
(5 \%)\end{array}$ & $\begin{array}{l}9 \\
(6 \%)\end{array}$ & $\begin{array}{l}8 \\
(7 \%)\end{array}$ & $\begin{array}{l}4 \\
(4 \%)\end{array}$ & $\begin{array}{l}4 \\
(7 \%)\end{array}$ & $\begin{array}{l}2 \\
(5 \%)\end{array}$ & & & & $\begin{array}{l}2 \\
(25 \%)\end{array}$ \\
\hline TP therapy & $\begin{array}{l}2 \\
(1 \%)\end{array}$ & $\begin{array}{l}2 \\
(1 \%)\end{array}$ & $\begin{array}{l}1 \\
(0.8 \%)\end{array}$ & & & & & & & \\
\hline Dry needling & $\begin{array}{l}1 \\
(0,6 \%)\end{array}$ & $\begin{array}{l}1 \\
(0,6 \%)\end{array}$ & $\begin{array}{l}1 \\
(0.8 \%)\end{array}$ & $\begin{array}{l}1 \\
(1 \%)\end{array}$ & & & & & & \\
\hline Traction & & $\begin{array}{l}1 \\
(0,6 \%)\end{array}$ & & $\begin{array}{l}3 \\
(3 \%)\end{array}$ & $\begin{array}{l}2 \\
(3 \%)\end{array}$ & $\begin{array}{l}2 \\
(5 \%)\end{array}$ & $\begin{array}{l}3 \\
(9 \%)\end{array}$ & $\begin{array}{l}2 \\
(11 \%)\end{array}$ & $\begin{array}{l}2 \\
(25 \%)\end{array}$ & \\
\hline Bed rest advice & $\begin{array}{l}1 \\
(0,6 \%)\end{array}$ & & & & & & & & & \\
\hline $\begin{array}{l}\text { Total modality } \\
\text { usage }\end{array}$ & 157 & 158 & 122 & 95 & 61 & 38 & 33 & 18 & 8 & 8 \\
\hline
\end{tabular}

* The total usage of the modalities is expressed as a percentage

Key: $\mathrm{Rx}=$ treatment, mobs $=$ mobilization, MFR $=$ myofascial release, $\mathrm{TP}=$ trigger point, $\mathrm{ET}=$ electrotherapy, $\mathrm{US}=$ ultrasound, IF = interferential therapy

Table 8: Five most common combinations of modalities used in first treatment session

\begin{tabular}{|l|l|}
\cline { 2 - 2 } \multicolumn{1}{c|}{} & Treatment combination \\
\hline Combination $\mathbf{1}$ & Spinal mobilizations, electrotherapy, back advice \\
\hline Combination $\mathbf{2}$ & Spinal mobilizations, electrotherapy, soft tissue mobilization/massage \\
\hline Combination 3 & Spinal mobilizations, soft tissue mobilization/massage, back advice \\
\hline Combination $\mathbf{4}$ & Spinal mobilizations, soft tissue mobilization/massage, exercises \\
\hline Combination 5 & Spinal mobilizations and electrotherapy \\
\hline
\end{tabular}

were underestimated in the study sample, based on the census information of the Western Cape which states that the female gender comprises the majority of the Western Cape population (Statistics South Africa 2001).

It appears that the initial pain scores of the study sample is higher than initial pain scores of patient populations reported in international studies (Hsieh et al 2004; Fritz et al 2008). This finding may be related to different etiological pain patterns and or differences in the pain management-seeking behaviours among patients presenting with acute LBP in Cape Town. Private acute LBP patients in Cape Town may only seek physiotherapy services when the pain is relatively worse compared to acute LBP patients in first world countries such as the USA (Fritz et al 2008). This behaviour may be attributed to the high financial cost of private health care in South Africa, as well as the lim- ited medical aid benefits available for physiotherapy.

Pain scores for pain experienced on the "day of treatment" and "pain the previous day" generally improved, but due to the absence of similar observational studies into acute LBP, it is difficult to interpret these findings into the context of other published reports. This finding may reflect the short-term effectiveness of physiotherapy for acute LBP when the patient has to reflect over a recent 
and short recall period, because the findings pertaining to "pain experienced in the past week" was less favourable. When patients reflected over the past week, the perception of their pain did not improve and worsened from the second to the sixth visit. This finding is alarming to physiotherapists as pain perception over the past week has been determined to be as reliable as momentary pain recorded electronically (Jamison et al 2006). The success in results could also be attributed to the clinical reasoning of physiotherapists who allow for individualization of treatment. However, regardless of physiotherapists possibly having good understanding of pain, it appears that managing and changing individual pain perceptions remain an ongoing challenge. It also signifies that physiotherapy management in the future may need to be revised to address patient empowerment in terms of selfmanagement skills which can be applied when patients experience episodes of pain. Furthermore, preventative measures should not only be advocated but put into practice by physiotherapists as this may reduce the recurrence of acute LBP episodes and ensure long-term perception of improvement. This finding pertaining to pain over the past week, potentially poses a serious threat to the profession, as the primary management goal should be to improve the patient's perception of their pain in the long-term, and not only momentary.

The mean disability scores improved significantly, but unlike pain assessment, we did not ask patients to recall their level of disability over a retrospective period of one week. However, the reduction in disability may be related to the improved momentary pain scores as well as the inclusion of exercises into the management regimens. The retrospective recall of disability should be included in future studies to assess whether patients perceive improved levels of disability over a longer period. The findings of this study illustrate no significant predictors of favourable outcomes. These analyses should be repeated in a larger sample as the sample size in this study is arguably too small for an appropriate level of confidence in the findings of the regression analyses.

With over 27 different combinations of treatment modalities used by the eight randomly-selected physiotherapy private practices, the variety in physiotherapy treatment for acute LBP makes it difficult to draw conclusions as to the most effective physiotherapy treatment regimens for acute episodes of idiopathic LBP in private practice. This concurs with previous literature, that physiotherapists in private practice vary widely in their preferred practices and this may be due to factors such as years of experience, expectations and preferences (Somerville et al 2008). Physiotherapists at primary level are often confused as to what is the most effective treatment for acute LBP (De Wet 2005). The use of evidence -based guidelines and the standardization of treatment is therefore necessary to reduce costs, improve patient care and improve service delivery (Mikhail et al 2005). Medical schemes can thus be guided with respect to tariff structures and efficiency as information regarding the burden of acute LBP can be useful to plot trends of LBP patients over time and provide directions about the educational needs of physiotherapists treating acute LBP in private practice.

\section{CONCLUSION}

The study illustrates that physiotherapy management based on the interpretation of individual physiotherapists in a real-life scenario, yield positive outcomes with respect to short-term pain and disability scores. However, pain perception of patients over a one week period reflects less favourable for physiotherapeutic interventions and reasons for this should be explored. Future studies incorporating larger samples should be conducted in order to ascertain the predictors of momentary and retrospective pain and disability outcomes of acute LBP patients. Furthermore, the variety in physiotherapy treatment across practices makes it difficult to draw conclusions as to the most effective physiotherapy treatment regimens for acute episodes of non-specific LBP in private practice. Future studies addressing the most effective combinations of physiotherapeutic interventions for acute LBP are therefore warranted.

\section{Acknowledgments}

The authors would like to acknowledge the South African Society of Physiotherapy's Orthopaedic Manipu- lation Therapy Group (OMTG) and the Faculty of Health Sciences, Stellenbosch University, for financial support during this study.

\section{Potential conflict of interest}

The authors declare that they have no conflicts of interest.

\section{REFERENCES}

Australian Acute Musculoskeletal Pain Guidelines Group: Evidence-based management of acute musculoskeletal pain. 2004 http://www7. health/gov/au/nhmrc/publications/pdf/cp94/pdf accessed September 2009

De Wet C 2005. Community Health Centre Statistics Unpublished data.

Ferguson C, Brownlee M, Webster V 2008. A Delphi study investigating consensus among expert physiotherapists in relation to the management of low back pain. Musculoskeletal Care 6(4):197-210

Fritz J, Cleland J, Speckman M, Brennan G, Hunter S 2008. Physical therapy for acute low back pain: Associations with subsequent healthcare costs. Spine 33:1800-1805

Hsieh L, Kuo C, Yen M, Chen T 2004. A randomized controlled trial for low back pain treated by acupressure and physical therapy. Preventative Medicine 39:168-176

Jamison R, Raymond S, Slawsby E, McHugo G, Baird J 2006. Pain assessment in patients with low back pain: comparison of weekly recall and momentary electronic data. The Journal of Pain 7:192-199

Koes B, van Tulder M 2006. Low back pain acute. Clinical Evidence 15:169-33

Louw Q, Morris L, Grimmer-Somers K 2007a. The Prevalence of low back pain in Africa: a systematic review. BMC Musculoskeletal 8:105

Louw Q, Morris L, Sklaar J 2007b. Evidence of Physiotherapeutic interventions for acute low back pain patients. South African Journal of Physiotherapy 63:7-14

Mikhail C, Korner-Bitensky N, Rossignol M, Dumas J 2005. Physical therapists' use of interventions with high evidence of effectiveness in the management of a hypothetical typical patient with acute low back pain. Physical Therapy 85:1151

New Zealand guidelines for acute low back pain guide. New Zealand Guidelines group 2004. www. nzgg.org.nz/guidelines/0072/acc1038_col.pdf accessed 09 September 2008

Somerville S, Hay E, Lewis M, Barber J, van der Windt D, Hill J, Sowden G 2008. Content and outcome of usual primary care for back pain. British Journal of General Practice 58:790-7

Statistics South Africa: Census 2001 Western Cape http://www.statssa.gov.za/census01/HTML/ WCPrimary.pdf (accessed September 2009) 